\title{
PAISAGENS EM TRÂNSITO: UM RETORNO À CIDADE DE ULISSES
}

\section{LANDSCAPES IN TRANSIT: A RETURN TO THE CITY OF ULISSES}

\author{
Francisca Marciely Alves Dantas ${ }^{1}$ \\ Maria Elvira Brito Campos ${ }^{2}$
}

\section{RESUMO}

Sabendo da importância da escritora portuguesa Teolinda Gersão no panorama lusófono, no âmbito do romance português contemporâneo, o propósito desta pesquisa é examinar de que forma os personagens apreendem subjetivamente a paisagem portuguesa na obra A cidade de Ulisses, publicada em 2011. Por se tratar de um romance que foi publicado após a Revolução dos Cravos, ocorrida em Portugal no ano de 1974, buscamos privilegiar o posicionamento crítico da autora, associando experiência e perspectiva imagética ao cenário cultural português.

PALAVRAS-CHAVE: Teolinda Gersão; espaço; paisagem; lugar.

\section{ABSTRACT}

Having knowledge of the Teolinda Gersão's importance in the lusophone panorama, in the scope of contemporary portuguese novel, the purpose of this research is to examine how the characters perceive subjectively the portuguese landscape on the literary work titled A cidade de Ulisses, published in 2011. Since this novel was published after the Carnation Revolution that took place in Portugal in 1974, we seek to focus on the critical position of the author, associating experience and imagery perspective with the portuguese cultural scene.

KEYWORDS: Teolinda Gersão; space, landscape; place. 
Nunca desembarcamos de nós. Nunca chegamos a outrem, senão outrando-nos pela imaginação sensivel de nós mesmos. As verdadeiras paisagens são as que nós mesmos criamos, porque assim sendo deuses delas, as vemos como verdadeiramente são, que é como foram criadas.

(PESSOA, 2006, p. 156)

Na confluência entre Literatura e Geografia, o texto narrativo $A$ cidade de Ulisses (2011), de Teolinda Gersão, instiga-nos a pensar na dimensão espacial a partir do crivo fenomenológico, buscando, desse modo, o desvendamento da ontologia suscitada na experiência do sujeito com o mundo ao seu redor. Como bem sabemos, tanto a prosa quanto a poesia portuguesa contemporânea põem em relevo o vislumbre dos excessos subjetivos que são delineados entre os personagens e os cenários poéticos, isto é, a configuração espacial nos escritos contemporâneos ressurge com uma tônica fenomenológica que traduz os inquietamentos, silêncios e sensações que perpassam os personagens. Com isso, é possível apurar que os desdobramentos da psique humana não se distanciam da arquitetura física redesenhada na obra literária.

A descrição ontológico-espacial dos trajetos percorridos pelos sujeitos de papel, no incessante pulsar entre pausa e movimento, é facilmente perceptível pelo leitor por meio da experiência com o texto literário, que possibilita caminhos elucidativos para compreender o modo como se corporifica conceitualmente o espaço fenomenológico, a partir de um viés geográfico humanista. Lancemos, a esse propósito, um fragmento da narrativa $A$ cidade de Ulisses da referida escritora:

E por outro lado também a literatura - o campo da palavra - se alargava e invadia outros domínios, procurava novas formas de se tornar visível, parecia já não lhe bastar o mundo confinado e silencioso do livro. Estava-se numa época de viragem, em que as formas se contaminavam e tudo era possível: outras maneiras de contar, mostrar, dar a ver, partilhar, experimentar, tornar visível. O leitor-espectador-visitante passava a ter um papel cada vez maior. Era levado a entrar nas obras, a circular por dentro delas, a perder-se e encontrar-se nelas. (GERSÃO, 2011, p. 22)

Tendo conhecimento de que Teolinda Gersão lançou-se no círculo literário português como romancista em 1981, com a obra O silêncio, e logo alcançou notoriedade e reconhecimento crítico, fato que ratifica o seu talento para arte literária - é importante lembrar que ela viveu em uma época de grandes metamorfoses, o que, de certa forma, contribuiu para revolucionar as Letras Portuguesas. É bem verdade que essas movimentações político-sociais pelas quais passou Portugal serviram de sustentáculo para o alargamento da expressão genuinamente portuguesa, no sentido de ampliar o olhar dos escritores sobre a sociedade que os cerca e das possibilidades 
múltiplas de traduzir seus anseios por meio da palavra poética. E isso fica explícito quando Teolinda Gersão busca estreitar o diálogo com outros campos do saber, o que cristaliza uma peculiaridade em sua jornada literária.

Essa característica alcança projeção, sobretudo, em obras como Paisagem com mulher e mar ao fundo e Os teclados, publicados respectivamente em 1982 e 1999, as quais criam zonas de contato com a História, as Artes Plásticas, a Música, a Arquitetura, a Filosofia, dentre outras. Como se pode observar, a escritora nos dá a entender que o seu fazer poético se revigora no entrelace intelectual com o intuito de "partilhar, experimentar, tornar visível" (GERSÃO, 2011, p. 22) a complexidade da condição humana, em suas múltiplas acepções. Tomando proveito desse excerto literário, adentraremos nessa análise em outro campo do conhecimento, a Geografia Humanista Cultural, objetivando circunscrever a experiência do sujeito nos domínios do espaço, do lugar e da paisagem no romance $A$ cidade de Ulisses (2011), a fim de visibilizar a dimensão poética do sujeito diante da geometria arquitetônica dos espaços.

A referida narrativa permite a visualização das imagens poéticas de Lisboa, que, conforme sugere o próprio título, carregam um sentimento de pertencimento, de posse, evidenciando uma ligação singular entre Ulisses e "sua" cidade. E aqui não há como deixar de mencionar o retorno à gênese mítica da fundação de Lisboa consubstanciado na figura emblemática e mitológica de Ulisses, convocada já no título, a servir de contraste entre o cosmopolitismo e o sagrado, o contemporâneo e o histórico. A viagem ao passado e ao presente proporcionada pela escrita fluida e carregada de material histórico de Teolinda Gersão revela uma Lisboa desejante, cenário de especulações amorosas e paixões excessivas, marcando uma visão tanto universal quanto particular dessa cidade, articulada por meio do olhar oblíquo dos personagens.

Uma vez que a temática abordada gira em torno da cidade, consideramos pertinente à discussão teórica aqui esboçada darmos visibilidade ao pensamento de Ítalo Calvino quando afirma: "outro símbolo, ainda mais complexo, que me permitiu maiores possibilidades de exprimir a tensão entre a racionalidade geométrica e o emaranhado das existências humanas, foi o da cidade" (CALVINO, 1990, p. 85), ou seja, não há como desvincular a existência do homem do espaço que ele ocupa. A arquitetura sensível do sujeito totaliza-se tendo o seu entorno como eixo norteador. Estamos explicando, portanto, que a vivência do homem no mundo que o cerca deixa aparente suas "cidades invisíveis", tomando de empréstimo as palavras de Calvino, evidenciando a tensão latente entre a visibilidade física e estrutural das cidades e a invisível subjetividade operada no sujeito quando da experiência no espaço.

Desse modo, a narrativa de Teolinda Gersão alcança a um só movimento não somente a descrição das ruas e bairros de Lisboa, mas também traça poeticamente os trajetos existenciais do sujeito a partir da sua 
localização espacial, sobrepondo racionalidade geométrica e emaranhado existencial humano, a ponto de dar conta da lacuna fragmentária que é a consciência humana. Como numa espécie de "texto-tela" o romance projeta ruas, avenidas, lojas e casas construídas literalmente por "palavras", cabendo ao leitor revigorar poeticamente e de forma singular essas imagens em sua mente. O teórico Renato Cordeiro Gomes explica, na obra Todas as cidades, a cidade, que é:

[...] estabelecido um jogo produtor de sentido que permite ver o invisível, que dá a ver essas cidades feitas de textos. "Dar a ver" é homólogo a "dar a ler": agenciamento da legibilidade, travessia pelas tramas da rede/texto, um espaço-tempo descontínuo, lacunar, em sua possível totalização, na fronteira porosa entre o conceito e a imagem [...]. (GOMES, 1994, p. 41)

A escrita de Teolinda Gersão concebe, então, a travessia do real ao imaginário manifestado por meio do olhar do leitor. As imagens cênicas desveladas a partir da construção dos segmentos linguísticos operam no âmbito do sensível, do poético. A imaterialidade do "sentir" se concretiza quando os personagens explicitam sua afetividade e estranhamento durante a experimentação com o seu entorno. Antes de darmos contornos conceituais às noções de espaço, lugar e paisagem na obra em análise, é imprescindível reconhecermos a importância da perspectiva experiencial, posto que essa abarca a maneira pela qual o indivíduo conhece e reconstrói sua realidade. A própria narrativa de Teolinda Gersão dá-nos abertura para refletir sobre esse processo, porém, a partir do contato com a obra de arte. Atentemo-nos ao fragmento:

Lembro-me de falarmos por vezes da instalação enquanto forma de arte: podia usar livremente elementos díspares, era uma forma híbrida, vampírica, um mundo em três dimensões que se era convidado a atravessar. Uma espécie de experiência por que se passava, que podia apelar a todos os sentidos, não só aos olhos mas também ao olfato, ao tacto, ao intelecto, como se se entrasse noutra visão, noutro lugar ou noutra vida. Uma experiência da qual no limite o espectador poderia (ou deveria) sair modificado. Porque a arte - pelo menos a que nos interessava - não era inócua nem inocente. Era perigosa, implicava um risco. (GERSÃO, 2011, p. 23)

A descrição do fragmento acima acerca da experiência diante da contemplação da obra de arte dá acesso ao pensamento geográfico humano, à medida que compreendemos que o sujeito vivencia, mesmo que inconscientemente, os diversos espaços e lugares pelos quais se movimenta, seja pelos sentidos e locomoção corporal, seja pela memória. A experiência do sujeito no espaço/lugar, assim como na contemplação da obra de arte, transporta-o a lugares e espaços não experienciados antes, além de promover sensações de afetividade ou repulsa. De uma forma ou de outra, não há como não argumentarmos que a dimensão espacial implica riscos ao 
sujeito, tendo em vista que ele não está imune às sensações provocadas pela vivência em seu entorno. Dessa forma, sempre existirá um elo subjetivo entre ambos. Compartilhando desse ponto de vista, o geógrafo humanista Yi-Fu Tuan explica que "as emoções dão colorido a toda experiência humana, incluindo os níveis mais altos do pensamento" (TUAN, 1983, p. 9). E continua explicando:

A experiência é constituída de sentimento e pensamento. $\mathrm{O}$ sentimento humano não é uma sucessão de sensações distintas; mais precisamente a memória e a intuição são capazes de produzir impactos sensoriais no cambiante fluxo da experiência, de modo que poderíamos falar de uma vida do sentimento como falamos de uma vida do pensamento. É uma tendência comum referir-se ao sentimento e pensamento como opostos, um registrando estados subjetivos, o outro reportando-se à realidade objetiva. De fato, estão próximos às duas extremidades de um continuum experiencial, e ambos são maneiras de conhecer. (TUAN, 1983, p. 11)

De fato, quando analisamos a experiência do sujeito na realidade espacial há que prevalecer a subjetividade em consonância com o aspecto objetivo da estrutura social e geográfica em que ele se encontra inserido. Além disso, não podemos esquecer que a relação concatenada entre sujeito e mundo é operada mediante a experiência, por meio de processos ligados à ordem do sentir. Com isso, constatamos que a relação sujeito-mundo torna-se única, consubstanciando, dessa forma, uma relação ontológica pautada no incessante imbricamento entre pessoas e lugares. Sob esse prisma teórico, "o sentido de lugar implica o sentido da vida e, por sua vez, o sentido do tempo" (OLIVEIRA, 2014, p. 3). Tomando parte desse fundamento teórico, a viagem pela cidade de Lisboa tem como ponto de especulação conceitual a relação erigida entre a cidade e os seus personagens, ancorada no arcabouço teórico da Geografia Humanista Cultural.

Teolinda Gersão nos apresenta na narrativa A cidade de Ulisses (2011) uma Lisboa redesenhada em diversas camadas temporais: faz uma incursão histórica, evidenciando a figura do herói grego Ulisses e o período áureo das Grandes Navegações, menciona ainda o fim da Ditadura Salazarista e a crise identitária que permeia o Portugal de hoje. É oportuno assegurar que a Lisboa representada no texto poético de Teolinda Gersão desnuda simultaneamente um país envolto em uma crise identitária e em uma espécie de conforto em torno do regresso ao sagrado, ao mitológico. E é esse cenário que servirá de pano de fundo aos movimentos ontológicoexistenciais e as "errâncias" de Paulo Vaz, o qual protagoniza cenas com Cecília Branco e Sara.

Ao tratarmos da relação de Paulo Vaz com a paisagem citadina, deparamos com sentimentos conflituosos e paradoxais, pois há uma afetividade por Lisboa simultânea a uma espécie de fuga, de descompasso em relação ao que vê e sente, conforme o personagem narra, quando da notícia sobre uma exposição sobre Lisboa: 
O projeto das várias exposições fazia algum sentido. Mas por que razão iriam ser itinerantes? É verdade que, para milhões e milhões de pessoas letradas do globo, Portugal não estava no mapa, era, quando muito, uma faixa estreita de terra diante da Espanha. E Lisboa era provavelmente a mais desconhecida das capitais da Europa, e uma das mais desconhecidas do mundo. Mas pretendiam exatamente o quê? Que os artistas ajudassem a colocar o país no mapa? Ironia do destino, num lugar onde a cultura era tão cronicamente maltratada. (GERS ̃̃O, 2011, p. 12)

Essa tensão sentida por Paulo Vaz delineia o que podemos reconhecer como uma realidade construída ao sabor de sensações conflitantes, ou seja, o desejo latente é que esse espaço resgate uma subjetividade que outrora ele sentiu. No entanto, no decorrer de seus movimentos geográficos, o que intuímos é uma constante oscilação de desejos em relação à sua terra natal, ou melhor, à oposição entre a cidade real e a cidade imaginada. Há, então, uma percepção que se altera no contraponto entre o passado e o presente, contrariando perspectivas e propondo "duas vias de leitura da cidade, [...] que respondem a uma simultaneidade contraditória de entusiasmo e ironia, de envolvimento afetivo e de crítica" (GOMES, 1994, p. 31). Num primeiro momento, o elo de afetividade corrobora-se pelo fato de a cidade ter sido cenário de seus encontros e desencontros amorosos. Paulo Vaz conhece a artista plástica Cecília Branco em Lisboa, quando era professor assistente de uma das cadeiras do primeiro ano. A partir disso, surge então uma profunda paixão entre ambos, eternizada na cidade lisboeta conforme demonstra o fragmento abaixo:

Lisboa estava lá e cercava-nos, era impossível não a olhar, não tropeçar nela a cada passo. Era o chão que pisávamos, um lugar que nos pertencia, porque era nele que nós tínhamos nos encontrado e nos amávamos. Mas no fundo não era Lisboa que procurávamos, era um ao outro e a nós mesmos que procurávamos em Lisboa. Éramos viajantes, e é para si próprios que os viajantes caminham. Querem saber quem são e onde moram. E, como escreveu Novalis, vamos sempre finalmente para casa. O modo como olhávamos a cidade tinha a ver conosco e com a nossa história. Desde logo porque o ponto de vista éramos nós. (GERSÃO, 2011, p. 66)

Lisboa é então, nessa circunstância, o lugar dos encontros, dos pertencimentos. Temos, portanto, um vínculo tão subjetivo quanto existencial. Do ponto de vista do artista plástico, esse encontro é possível porque Lisboa é antes de tudo uma cidade que tem "um estatuto singular, uma cidade real criada pela personagem de um livro, contaminada portanto pela literatura, pelo mundo da ficção e das histórias contadas" (GERSÃO, 2011 , p. 35). No plano estético, as questões ontológico-espaciais constroem-se poeticamente na dualidade ser/estar. Não é possível ser sem estar no trajeto humano e aqui esboçamos a relação configurada entre sujeito e sua localização no mundo. Dessa forma, desnudamos tanto a paisagem geográfica, na qual está inserido o personagem, quanto a sua paisagem existen- 
cial. Com base na Geografia Humanista Cultural, o geógrafo Eric Dardel explica que a paisagem é uma "convergência, um momento vivido, uma ligação interna, uma 'impressão', que une todos os elementos” (2015, p. 30). E ainda argumenta que:

Há, na paisagem, uma fisionomia, um olhar, uma escuta, como uma expectativa ou lembrança. Toda espacialização geográfica, porque é concreta e atualiza o próprio homem em sua existência e porque nela o homem se supera e se evade, comporta também uma temporalização, uma história, um acontecimento. (DARDEL, 2015, p. 33)

No caso, a paisagem deixa de ser apenas uma estrutura geográfica e enlaça-se à vivência humanística, deixando transparecer um tempo, um fato e um sujeito. Contingencialmente, ainda que o homem se movimente de forma constante, sua existência sempre estará vinculada a uma paisagem geográfica. A Lisboa construída sob o olhar poético de Teolinda Gersão transfigura metaforicamente a experiência de Paulo Vaz nessa paisagem. A narrativa desenrola-se em torno de uma exposição no Centro de Arte Moderna, idealizada por Paulo Vaz e Cecília Branco, cujo tema é a cidade de Lisboa. Apesar da satisfação com a realização do projeto, Paulo Vaz mostra-se um pouco apático no que se refere à escolha do tema, conforme sugere o excerto:

Uma cidade construída pelo nosso olhar, que não tinha de coincidir com a que existia. Até porque também essa não existia realmente, cada um dos dez milhões de portugueses e dos milhões de turistas que por ela andavam tinha de Lisboa a imagem que lhe interessava, bastava ou convinha. Não havia assim razão para termos medo de tocar-lhe, podíamos (re)inventá-la, livremente. (GERSÃO, 2011, p. 33)

Imprimir em suas telas uma Lisboa "imaginada" a partir da realidade vivenciada parecia aos olhos de Paulo Vaz uma ideia um pouco desconfortável. Contudo, o contentamento de Cecília Branco diante do projeto o acalentava amorosamente. No passeio pelas ruas de Lisboa, Paulo Vaz e Cecília Branco detêm dentro de si manifestações subjetivas díspares, sem pontos de contato. A mesma Lisboa desperta nos transeuntes sensações e deslocamentos diversos, que se sobrepõem e constituem a unicidade de cada sujeito. Isso confirma o fato de que "a imagem que temos do lugar é sempre pessoal. Nossas imagens do passado e do futuro são imagens do presente continuamente recriadas" (OLIVEIRA, 2014, p. 13). O universo diegético construído por Teolinda Gersão na narrativa em questão sobrepõe no mesmo espaço textual duas impressões acerca de Lisboa. De um lado, temos o olhar encantador de Cecília Branco e, de outro, uma posição um tanto desinteressada por parte de Paulo Vaz, como demonstra o trecho que se segue:

Tudo era igual nessa manhã, quando acordaste e foste à janela. Mas tudo era diferente. Havia lá em baixo a mesma rua, as mesmas casas, as mesmas lojas de legumes e fruta, os mesmos quiosques de jornais, as mesmas pessoas fariam compras como habitualmente, trocariam com quem estava atrás do balcão as mesmas frases banais de "obrigado" e "bom dia". 
[...] Mas tudo isso, tão igual a sempre, era diferente. O mundo transformara-se noutro, e só tu sabias. Por isso sorrias para ti própria, caminhando na rua numa espécie de estado de graça, como se nada ruim te pudesse atingir e a felicidade fosse uma coisa palpável, concreta, que levavas na mão, fechada dentro do bolso, e te pertenceria para sempre. [...] Mas tu continuavas a falar, havia dias, semanas, meses. Parecia-me. Como se nada pudesse quebrar o encantamento nem interromper a tua voz. A cidade iluminava-se e tudo que olhavas tinha relação comigo [...]. (GERSÃO, 2011, p. 26-27)

A partir desse trecho apreendemos em Paulo Vaz o extravasamento de uma inconstância aparente, visto que ao mesmo tempo em que Lisboa é para o personagem cenário de paixões arrebatadoras é também um país que tem cores cinzentas, indiferente: "Procurei a Lisboa das gaivotas, do céu claro, do rio, mas vinha ao meu encontro a outra, a da sopa dos pobres no Intendente, dos sem-abrigo, dos desempregados, dos mendigos [...]" (GERSÃO, 2011, p. 165), demonstrando que "os desejos agora são recordações” (CALVINO, 2003, p. 6). Contudo, Cecília Branco sente exatamente o contrário: Lisboa é um país a ser conquistado cotidianamente e confunde-se com suas vivências quando lembramos que ela está perdidamente apaixonada pelo artista plástico. Além disso, o narrador protagonista chama atenção para um aspecto referente à sua amante quando diz:

Vinhas, desde logo, de uma terra diferente. Nasceste em Moçambique em sessenta e quatro. Em setenta e quatro tinhas dez anos e não teve para ti qualquer significado o fato de haver uma revolução em Portugal. De resto na altura Portugal, como o resto do mundo, excepto África, eram para tu apenas superfícies delimitadas por linhas e pintadas de cor, no grande mapa dos continentes. (GERSÃO, 2011, p. 69)

Talvez esse dado justifique o fato de ambos possuírem perspectivas diferentes acerca de suas experiências na cidade lisboeta. Partindo dessa constatação, elegemos oportunamente o pensamento do filósofo francês Maurice Merleau-Ponty, no seu livro Fenomenologia da Percepção (1999), quando esclarece que "tudo aquilo que sei do mundo, mesmo por ciência, eu o sei a partir de uma visão minha ou de uma experiência do mundo sem a qual os símbolos da ciência não poderiam dizer nada" (MERLEAU-PONTY, 1999, p. 3). E dessa forma compreendemos o motivo dos olhares distintos dos referidos personagens pelas ruas de Lisboa. Além disso, sabendo que a experiência imagética pertence a cada sujeito e organiza-se de forma ordenada na consciência, obedecendo aos impulsos temporais e espaciais de cada um, é seguro afirmar que "a percepção e os julgamentos do meio ambiente das pessoas nativas e dos visitantes mostram pouca coincidência porque suas experiências e propósitos pouco têm em comum" (TUAN, 2012, p. 338). Cada lugar vivenciado pelo sujeito suscita percepções adversas a depender da marcação temporal e do modo como a consciência humana responde a esses estímulos externos. Em outras palavras, um mesmo lugar pode provocar em um determinado momento afetividade e, passado algum tempo, motivar distanciamento, isso vai depender 
do sujeito que a vivencia. Assim como o mundo se transforma a todo instante, o indivíduo também acompanha o ritmo dessas mudanças. No caso em questão, Cecília Branco tem referências distintas de Paulo Vaz no que concerne à ligação com Lisboa, conforme ele narra: se "sentias em casa em Lisboa, fazia sentido que quisesses voltar" (GERSÃO, 2011, p. 71).

A noção de lugar e espaço, princípios norteadores da Geografia Humanista Cultural, camuflada de forma dinâmica e inteligível no texto poético de Teolinda Gersão, vem à tona quando buscamos a marcação temporal e espacial dos sujeitos fictícios em meio à sobreposição das camadas do tempo, circunscrevendo, desse modo, a dialética tempo/sujeito/mundo. A escritora portuguesa arquiteta a narrativa fazendo coexistir o contemporâneo e o histórico, o passado e o presente, cuja tensão se revigora na movimentação dos corpos e do olhar, conforme ilustrado no fragmento:

Lisboa, pelo contrário, estava historicamente ligada à Grécia, às rotas marítimas e comerciais dos gregos. (Existem ainda hoje, numerosos vestígios e peças de cerâmicas gregas em Almaraz, perto de Lisboa, além de noutros lugares, como Aveiro, Alcácer do Sal e Algarve.) Sobre a relação de Ulisses com Lisboa não tínhamos portanto que inventar nada, já tudo tinha sido inventado havia dois mil anos, e essa história, porque tinha pés para andar, continuara a andar pelos séculos fora. Que marcas do mito se encontravam ainda em Lisboa? Na verdade algumas: No Castelo de São Jorge a Torre de Ulisses, que já foi Torre do Tombo, onde escreveram Fernão Lopes e Damião de Góis; [...]. Não haveria talvez muitas mais memórias, pelo menos agora não estávamos a ver outras, mas registávamos pelo menos estas. (GERSÃO, 2011, p. 35)

A percepção concomitantemente perscrutadora e poética de Paulo Vaz põe em paralelo uma Lisboa atual e a cidade que outrora fora fundada por Ulisses. Sobre a expectativa de alcançar o histórico através da experiência imagética, cabe aqui enfatizar o ensinamento lúcido de que "perceber o contorno fantasmagórico de uma paisagem antiga, sob a capa superficial do contemporâneo, equivale a perceber, intensamente a permanência dos mitos essenciais" (SCHAMA, 1996, p. 27), ou seja, apesar da atualização espacial, há na escrita gersiana uma relação mítica a ser buscada na memória individual e coletiva. Ainda que a plausibilidade da exposição artística justifique-se na ânsia de transcender o olhar diante da arquitetura física e de expor os assombros da arte contemporânea, não há como não reconhecer que essa experiência está imbuída de concepções tanto individuais quanto coletivas, demarcando a interseção entre o real e o imaginário. Assemelham-se, então, na paisagem de Lisboa, a história de Ulisses e a de Paulo Vaz, confirmando o fato de que "a cidade se embebe como uma esponja dessa onda que reflui das recordações e se dilata" (CALVINO, 2003, p. 7).

Delinear o trajeto de Paulo Vaz é falar de uma Lisboa que faz emergir a todo instante a conexão eu/mundo. $\mathrm{O}$ artista plástico sempre foi afeito às passagens pelo mundo e reconhece seu país do seguinte modo: 
Situada no Extremo Ocidente, entalada entre o mar e a Espanha, tão amiga quanto inimiga, Lisboa procurou no mar uma saída. E partiu. O verbo partir fazia parte de nós, era o lado do desejo, da insatisfação, da ânsia que não se tinha. Imaginávamos facilmente Lisboa levando e trazendo, porto de passagem. Assimilando o que não conhecia, tornando parte de si o exótico, o ex-óptico, o que está para lá do que os olhos podiam alcançar. [...] Lisboa, onde agora aportavas, estava no fim de dois oceanos. Ou no princípio. Era um lugar de chegar e de partir, uma cidade aberta. Debruçada sobre um rio que a levava ao mar. (GERSÃO, 2011, p. 47 e 71)

A Lisboa imaginada, metaforicamente, procurou no mar uma saída e partiu. Assim também o fez o artista plástico: partiu em busca de novos horizontes e lugares, revelando a unicidade entre paisagem e sujeito. Com o término de seu romance com Cecília Branco, ele não viu nenhum motivo que justificasse sua permanência na cidade.

O cerne da questão que queremos trazer é o sentido de lugar. Estamos diante de um personagem, que, apesar de viver em sua terra natal, permanece todo o tempo em busca da posse de seu lugar no mundo, que parece, ainda que de relance, não ser Lisboa e nenhum outro canto do universo, uma vez que "não sabe nada sobre aquele estrangeiro [Paulo Vaz], não sabe que ele está de passagem, que estará sempre de passagem” (GERSÃO, 2011, p. 24).

Analisando sob o prisma conceitual da Geografia Humanista Cultural, a ideia de lugar alcança corporeidade quando o sujeito reconhece que há uma ligação forte com o seu entorno, ou seja, "é o lugar experienciado como aconchego que levamos dentro de nós" (OLIVEIRA, 2014, p. 18). Nos princípios teóricos de Yi-Fu Tuan o "lugar é uma pausa no movimento" (TUAN, 1983, p. 153) sugerindo uma espécie de identidade espacial e conferindo "uma profunda associação e pertencimento, mas também imobilidade" (OLIVEIRA, 2014, p. 24) por parte do sujeito. Reportando-nos à superfície imaginada da narrativa de Teolinda Gersão e seu personagem masculino, devemos ressaltar que Paulo Vaz não se reconhece em Lisboa, apesar de visualizarmos pontos de convergência que iluminam experiências afetivas entre ele e a paisagem. Esse descompasso entre Paulo Vaz e a cidade lisboeta pode ser percebido no fragmento circunscrito abaixo, quando ainda convivia com Cecília Branco:

Houve um boom na Bolsa e em Outubro de 87 as Bolsas de todo o mundo entraram em queda livre. Só se falava de 1929. Tudo isto são memórias soltas, a realidade foi naturalmente muito mais complexa. No entanto, ainda conservo alguns recortes de jornais, que agora folheio para recordar fragmentariamente algo do que então acontecia. De qualquer modo no meio da crise generalizada a nossa felicidade pessoal era um bem precioso, um pequeno milagre a defender ciosamente da enorme turbulência à nossa volta. Vivíamos em equilíbrio num país em desequilíbrio, mas acreditávamos que era um mau momento, transitório. Pediam-nos sacrifí- 
cios brutais, mas depois de uma revolução e de um período pós-revolucionário conturbado estávamos dispostos a pagar um alto preço por um país democrático e normal. Mas não é disso que quero falar-te agora, Cecília. Prefiro falar-te do tempo só nosso que vivemos nessa altura em Lisboa. (GERSÃO, 2011, p. 110)

Aqui Teolinda Gersão lança mão do material histórico para contar a história de Paulo Vaz. Lisboa é, então, a metáfora da arquitetura subjetiva de seu cidadão português. Os declínios subjetivos que o perturbam podem ser visualizados da seguinte forma: do ponto de vista individual a cidade é, ainda que circunstancialmente, o lugar onde possui "ligações inextrincáveis com o ser, com a nossa própria existência" (RELPH, 2014, p. 29). Por outro lado, do ponto de vista coletivo, observando o artista plástico em meio a outros tantos portugueses, deparamo-nos com um sujeito distante e apático diante do país que desponta aos seus olhos.

Viver no estrangeiro acarreta dificuldades, e como era de esperar encontrei algumas. Mas não posso dizer que sofresse, ou pelo menos que sofresse demasiado, por estar longe do meu país, embora pensasse nele muitas vezes. Sentia-me igual a milhões de portugueses, emigrantes como eu. Portugal é um país de emigrantes. Em todos os lugares vivi no meio de artistas, muitos deles estrangeiros, e criávamos um certo sentido de comunidade. Houve alguns de quem fiquei amigo e com quem me mantive em contato ao longo dos anos. Pelo menos para mim, era comunidade quanto baste. No fundo nunca tive grande sentido de pertença, seria incapaz de pertencer por exemplo a uma igreja ou a um partido político, embora tivesse preocupações sociais e o meu sentido ético fosse exigente, desde logo em relação a mim próprio. Mas nunca abri mão de uma condição um tanto distanciada, da liberdade de não pertencer. Na verdade, também em Portugal o meu modo de estar era esse. (GERSÃO, 2011, p. 159-160)

Nessa aparente oscilação, há que argumentar que a cidade de Lisboa é para Paulo Vaz "o lugar consciente do tempo social e histórico, recorrente e mutável, no transcorrer das horas do tempo em um espaço sentido dentro de um lugar interior ou exterior" (OLIVEIRA, 2014, p. 1516). O posicionamento de Paulo Vaz acerca de Portugal é motivado tanto por circunstâncias históricas quanto subjetivas. Ele tem consciência das intensas transformações históricas, sociais e culturais pelas quais passou Portugal após a deflagração emblemática da Revolução dos Cravos e de como essa conjuntura rasurou a consciência nacional. Isso, de certa forma, ficou registrado na memória e na paisagem de Lisboa.

Pensar em Portugal é para o protagonista sentir um lugar que faz uma curvatura em direção tanto ao seu passado quanto ao seu futuro, o que se mostra evidente quando ele, ao observar a paisagem portuguesa, depara-se com a história de sua fundação e o misticismo em torno disso, sobretudo quando há menção a Ulisses. Isso confirma a tese do crítico e ensaísta Eduardo Lourenço quando afirma que há, "em suma, uma modulação daquela particular maneira de sentir a vida que os portugueses 
resumem na palavra-mito da sua cultura, a saudade" (LOURENÇO, 1999, p. 39). Há, desse modo, um redimensionamento crítico e sutil da paisagem portuguesa que se apresenta na narrativa de Teolinda Gersão, visível por meio da relação edificada entre o homem e a Terra.

\section{REFERÊNCIAS BIBLIOGRÁFICAS}

CALVINO, Ítalo. As cidades invisíveis. Tradução de Diogo Mainardi. Rio de Janeiro: O Globo, 2003.

. Seis propostas para o próximo milênio. Tradução de Ivo Barroso. São Paulo: Companhia das Letras, 1990.

DARDEL, Eric. O Homem e a Terra: natureza da realidade geográfica. Tradução de Werther Holzer. São Paulo: Perspectiva, 2015.

GERSÃO, Teolinda. A cidade de Ulisses. Portugal: Sextante, 2011.

GOMES, Renato Cordeiro Gomes. Todas as cidades, a cidade. Rio de Janeiro: Rocco, 1994.

LOURENÇO, Eduardo. A nau de Ícaro e Imagem e miragem da lusofonia. São Paulo: Companhia das Letras: 1999.

MERLEAU-PONTY, Maurice. Fenomenologia da percepção. 3. ed. São Paulo: Martins Fontes, 1999.

OLIVEIRA, Lívia. O sentido de lugar. In: JR. MARANDOLA, Eduardo; HOLZER, Werther; OLIVEIRA, Lívia (Orgs). Qual o espaço do lugar? São Paulo: Perspectiva, 2014, p. 3-16.

RELPH, Edward. Reflexões sobre a emergência, aspectos e essência do lugar. In: JR. MARANDOLA, Eduardo; HOLZER, Werther; OLIVEIRA, Lívia (Orgs). Qual o espaço do lugar? São Paulo: Perspectiva, 2014, p. 17-32.

SCHAMA, Simon. Paisagem e memória. Tradução de Hildegard Feist. São Paulo: Companhia das Letras, 1996.

TUAN, Yi-Fu. Topofilia: um estudo da percepção, atitudes e valores do meio ambiente. Tradução de Lívia de Oliveira. Londrina: Eduel, 2012.

Espaço e lugar: a perspectiva da experiência. Tradução de Lívia de Oliveira. São Paulo: DIFEL, 1983.

Recebido para publicação em 31/05/2018

Aprovado em 20/08/2018

\section{NOTAS}

1 Graduada em Letras - Língua e Literaturas Brasileira e Portuguesa pela Universidade Federal do Piauí (2012). Mestra em Letras: Estudos Literários pela mesma universidade (2016).

2 Graduação em Letras pela Universidade Estadual do Sudoeste da Bahia (1989), Mestrado em Estudos Comparados de Literaturas de Língua Portuguesa pela Universidade de São Paulo (1999), Doutorado em Estudos Comparados de Literaturas de Língua Portuguesa pela Universidade de São Paulo (2003) e Pós-doutorado pela Universidade de Coimbra (2013). Atualmente, é professora adjunta da Universidade Federal do Piauí. 